(c) 2017, Elsevier. Licensed under the Creative Commons Attribution-NonCommercial-NoDerivatives 4.0 International

http://creativecommons.org/licenses/by-nc-nd/4.0/

\title{
NiO/nanoporous carbon heterogeneous Fenton catalyst for aqueous Microcystine-LR
}

\section{decomposition}

Wan-Kuen Jo ${ }^{\mathrm{a}}$, S. Karthikeyan ${ }^{\mathrm{a}, \mathrm{b}, \mathrm{c}}$, Mark A. Isaacs, ${ }^{\mathrm{b}}$ Adam F. Lee ${ }^{\mathrm{b}}$, Karen Wilson ${ }^{\mathrm{b}}$, Seung-Ho Shin $^{\text {d }}$, Jun-ho Lee ${ }^{\mathrm{e}}$, Mo-Keun Kim ${ }^{\mathrm{e}}$, Byung-Sik Park ${ }^{\mathrm{f}}$, and G. Sekaran ${ }^{\text {c* }}$

${ }^{a}$ Department of Environmental Engineering, Kyungpook National University, Daegu 702-701, South Korea.

${ }^{b}$ European Bioenergy Research Institute, Aston University, Aston Triangle, Birmingham B4 7ET, United Kingdom.

${ }^{c}$ Environmental Technology Division, Council of Scientific \& Industrial Research (CSIR), Central Leather Research Institute (CLRI), Chennai 600 020, India.

${ }^{d}$ Department of Health Environment, Deagu Health College, 15 Youngsong-Ro, Buk-Gu, Deagu 702-722, Korea.

${ }^{e}$ GyeongSangBukdo Government Public Institute of Health and Environment, Yeongcheon, Kyungpook,770-800, Korea.

${ }^{f}$ Department of Pharmaceutical Engineering, International University of Korea Jinju, Gyeongnam, 660-759, S. Korea.

*Corresponding authors. E-mail address: ganesansekarn@gmail.com (G.Sekaran);

\begin{abstract}
The efficacy of $\mathrm{NiO}$ nanoparticles dispersed on a nanoporous carbon matrix (NiO/NPC) for microcystine-LR degradation in aqueous media is reported. The NiO/NPC catalyst was characterized by porosimetry, scanning electron microscopy, elemental analysis, powder X-ray diffraction, and X-ray photoelectron spectroscopy, and applied to the oxidative degradation of microcystine-LR contaminated water in the presence of hydrogen peroxide as a function of $\mathrm{pH}$ under ambient conditions. Optimal MC-LR removal efficiency was $86 \%$ at neutral pH catalyzed by this heterogeneous Fenton-like (NiO/NPC with $\left.\mathrm{H}_{2} \mathrm{O}_{2}\right)$ process, which has the added benefit of avoiding secondary metal pollution during microcystine-LR degradation. NiO/NPC represents an earth abundant catalyst for generating hydroxyl radicals to facilitate environmental depollution of organic pollutants from wastewater.
\end{abstract}

Keywords: Nickel; Carbon; Heterogeneous catalyst; Oxidation; Microcystine-LR 


\section{Introduction}

Advanced oxidation technology (AOT) is one of the most effective methods for removing non-biodegradable and persistent organic compounds in industrial wastewater [1]. Examples of AOTs include Fenton oxidation [2], photocatalytic oxidation [3], photo-Fenton oxidation [4], ozonation [5], catalytic wet air oxidation [6], and electro catalytic oxidation process [7], electroFenton oxidation [8-10] which have all been effectively applied to facilitate the oxidative removal of persistent organic compounds in wastewater. AOTs are generally assumed to operate through $\bullet \mathrm{OH}$ radicals as the major species responsible for the unselective mineralization of organic pollutants $[11,12][13]$. Fenton oxidation is one of the most widely studied AOT in which a homogeneous ferrous salt and hydrogen peroxide react to liberate hydroxyl radicals in aqueous media [14], however efficiency is poor and confined to $\mathrm{pH} 2-4$ [15]. Furthermore, iron hydroxide sludge and other by-products are produced during Fenton treatment of organic pollutants, with metal contaminants themselves necessitating further water treatment [16].

Porous carbons such as activated carbon, graphene, and multi-walled carbon nanotubes [17-19] are attractive catalyst supports due to their high surface areas, tunable porosity and excellent chemical and thermal stability. For example, Ni nanoparticles over N-doped nanoporous carbons have been employed for nitrobenzene hydrogenation to $p$-aminophenol [20], while Kim et al [21] reported recently on the continuous removal of toxic acidic vapor via a nanostructured copper/nickel-coated nanoporous carbon sheets. He et al [22] also reported on the use of nickel nanoparticles as heterogeneous Fenton analogues for the degradation of crystal violet dye in aqueous solution under microwave irradiation. Heterogeneous, graphene oxide (GO) supported $\mathrm{NiFe}_{2} \mathrm{O}_{4}$ catalysts have also shown promise for the photo-Fenton degradation of methylene blue, rhodamine B and malachite green dyes under visible light irradiation [23]. We 
reported previously the excellent catalytic activity of $\mathrm{CuO}$ nanoparticles dispersed throughout nanoporous carbon as a heterogeneous Fenton catalyst for degradation of toxic microcystine (MC)-LR in water [24]. Porous carbon supported $\mathrm{FeO}_{\mathrm{x}}$ and $\mathrm{Co}_{3} \mathrm{O}_{4}$ catalysts have also been used to remove refractory organic compounds in industrial wastewater [25, 26]. Nickel oxide nanoparticles are less investigated for dye degradation, however a laboratory scale study of wastewater treatment containing mono azo Orange II dye showed them as efficacious for decolorization under acidic conditions. Since nickel nanoparticles are prone to sintering during oxidative degradation reactions [27], and oxidized carbons are known to inhibit metal leaching in aqueous media, it is of interest to explore the performance of Ni nanoparticles dispersed over high area carbons for water depollution.

Here we report the first study of MC-LR oxidative degradation over rod-like NiO/nanoporous carbon (NPC) heterogeneous Fenton catalysts and demonstrate their aqueous operation at neutral $\mathrm{pH}$.

\section{Materials and methods}

\subsection{Synthesis of nickel catalyst supported on porous carbon}

A NiO/NPC heterogeneous Fenton catalyst was synthesized from rice husk (an agricultural by-product), which contained silicon as the principal inorganic component. Synthesis of the nanoporous carbon support was performed according to a literature procedure [28]. The rice hush sample was soaked in hydrofluoric acid (HF) for one week to remove silicon, and subsequently washed with deionized water several times until washings with a neutral $\mathrm{pH}$ were obtained. The resulting nanoporous carbon material is labelled NPC. Nanoporous carbonsupported nickel catalyst (NiO/NPC) was prepared using a hydrothermal method in two steps: NPC was oxidized using $6 \mathrm{M} \mathrm{HNO}_{3}$ at its boiling point for $4 \mathrm{~h}$ and the sample was then dried at 
$100{ }^{\circ} \mathrm{C}$. Next, about $2 \mathrm{~g}$ of the oxidized NPC was introduced into a $200 \mathrm{~mL}$ of $0.01 \mathrm{M}$ nickel (II) nitrate hexahydrate solution in nitric acid for $5 \mathrm{~h}$. The mixture was heated at $110{ }^{\circ} \mathrm{C}$ for $8 \mathrm{~h}$ under an inert atmosphere, and the resulting solid was subsequently annealed at $400{ }^{\circ} \mathrm{C}$ under a nitrogen atmosphere for $5 \mathrm{~h}$. Thereafter, the nanoporous carbon-supported nickel catalyst was washed several times using deionized water. The synthesized samples were washed and dried at $110{ }^{\circ} \mathrm{C}$ to afford the NiO/NPC catalysts. Fig. 1 illustrates the synthetic protocol for the NiO/NPC catalyst.

\subsection{Characterization of nanoporous carbon (NPC) and NiO/NPC}

The physicochemical properties of the nanoporous carbon and supported nickel analogue were examined via electron paramagnetic resonance (EPR), X-ray photoelectron spectroscopy (XPS), X-ray powder diffraction (XRD), scanning electron microscopy (SEM), $\mathrm{N}_{2}$ porosimetry, and Fourier Transform infra-red (FT-IR). Crystalline phases were analyzed using a Rich Siefert 3000 XRD diffractometer with $\mathrm{Cu} \mathrm{K}_{\alpha 1}$ radiation $(\lambda=1.5406 \AA)$. Surface morphology was explored using a Quanta 200 FEG scanning electron microscope. Thermogravimetric analysis (TGA) was collected on a TGA Q50 (V20.6 Build 31) thermal analyzer employing a heating rate of $10{ }^{\circ} \mathrm{C}$ per minute under $\mathrm{N}_{2}$. Surface areas and porosity was measured using a Micromeritics ASAP 2020 analyzer. Free electron density was determined via EPR spectroscopy at room temperature using an EPR tube in a Bruker ESP 300E spectrometer operated at a microwave frequency of $9.399 \mathrm{GHz}$, with a modulation frequency of $100 \mathrm{kHz}$, a modulation amplitude of $3.0 \mathrm{G}$, microwave power of $3.188 \mathrm{~mW}$, center field of $3342 \mathrm{G}$, sweep width of $3000 \mathrm{G}$, and a sweep time of 20.972 s. XPS analysis was performed using a SPECS XPS system and 150 W Al $\mathrm{K}_{\alpha}$ radiation. Ni 2p and $\mathrm{C}, \mathrm{O}$ and $\mathrm{N}$ 1s XP spectra were obtained with $25 \mathrm{eV}$ pass energy, with binding energies referenced to the $\mathrm{C}$ 1s binding energy of adventitious carbon at $284.4 \mathrm{eV}$. FT- 
IR measurements were performed using a Perkin-Elmer FT-IR Spectrometer scan range 4000$400 \mathrm{~cm}^{-1}$ averaged over 20 scans. Approximately $0.1 \mathrm{~g}$ of the NPC support or Ni/NPC catalyst were mixed with $\sim \mathrm{g}$ of $\mathrm{KBr}$ (Merck, Germany), and pelletized $1 \mathrm{~mm}$ x $13 \mathrm{~mm}$ o.d. disks.

\subsection{Degradation of Microcystine-LR by NiO/NPC catalyst}

A fluidized bed reactor was developed using a $5 \mathrm{~mm}$ thick polyacrylic leaf (Indian patent application number: 2728/DEL/2012). The total reactor volume was $550 \mathrm{~mL}$ with a working volume of $500 \mathrm{~mL} .1 \mathrm{~g}$ of the Ni/NPC catalyst was first added to the reactor, with oxygen then supplied to promote MC-LR degradation by the fluidized catalyst. About $100 \mu \mathrm{g} / \mathrm{L}$ of MC-LR containing water was fed into the bottom of flow reactor in a batch study. Degradation studies were performed for 120 min with aliquots of the reaction mixture periodically sampled to investigate the progress of MC-LR degradation. The optimal hydrogen peroxide concentration was established by varying the hydrogen peroxide concentration employed, and the effect of time, $\mathrm{pH}$, and catalyst loading were also studied: the length of reaction time was varied between 10 to $120 \mathrm{~min}$; experiments were conducted at $\mathrm{pH} \mathrm{3,} 7$ or 9 through $\mathrm{H}_{2} \mathrm{SO}_{4}$ or $\mathrm{NaOH}$ addition while aerating the system.

\section{Results and discussion}

\subsection{Characteristics of $\mathrm{NiO} / \mathrm{NPC}$}

Structural properties of the NiO/NPC catalyst were first analyzed by XPS and the resulting spectra shown in Fig. 2 (a-d). The C 1s spectrum is dominated by $\mathrm{CHx}$ species at 284.4 $\mathrm{eV}$ binding energy characteristic of graphitic $\mathrm{sp}^{2}$-bonded amorphous carbon, ether or alcohol functions at $284.6 \mathrm{eV}$, and carboxylate functions at $288.5 \mathrm{eV}$ [20, 29]. Multiple oxygen chemical environments were observed at 531.2, 532.8 eV, 535.5 and $531.2 \mathrm{eV}$ indicating a broad distribution of oxygenate functionalities including $(\mathrm{C}-\mathrm{O}-\mathrm{C},-\mathrm{C}=\mathrm{O}$ and $\mathrm{O}-\mathrm{C}=\mathrm{O})$ were present in 
the NiO/NPC catalyst consistent with the surface carbon species. Fig. 2c shows the Ni 2p $3 / 2$ XP spectra of the NiO/NPC catalyst, which exhibits two photoelectron peaks at 854.1 and $856.1 \mathrm{eV}$ both arising from tetrahedral $\mathrm{Ni}^{2+}$ spin-orbit split species within $\mathrm{NiO}$ [30], in addition to three shake-up satellites at 857.4, 859.9, and 861.5.4 eV with various shake-up satellites. There was no evidence of metallic nickel.

The XRD pattern of the parent NPC support is shown in Fig. 3 and exhibited two reflections at $2 \theta=22.95^{\circ}$ and $43.6^{\circ}$, consistent with the (002) and (100) planes of graphite [31]. The corresponding pattern of $\mathrm{NiO} / \mathrm{NPC}$ exhibited additional reflections at $2 \theta=37.27^{\circ}, 42.89^{\circ}$, $61.37^{\circ}$, and $79.64^{\circ}$, associated with (111), (200), (220), and (222) planes of nickel oxide [32]. The volume-averaged crystallite size of the NiO phase as determined using the Scherrer equation was $82 \mathrm{~nm}$ in diameter. The adsorption-desorption isotherm and pore size distribution for $\mathrm{NiO} / \mathrm{NPC}$ are shown in Fig. $4 \mathrm{a}$ and $\mathrm{b}$; the total surface area and total pore volume of the $\mathrm{NiO} / \mathrm{NPC}$ catalyst were $379 \mathrm{~m}^{2} / \mathrm{g}$ and $0.26 \mathrm{~cm}^{3} / \mathrm{g}$, respectively, showing negligible decrease relative to the parent activated carbon [33]. The NiO/NPC comprised a mix of rough sheets and rod-like morphologies spanning the micron scale (Fig. 5a-c). EDX elemental analysis of the NiO/NPC catalyst (Fig. 5d) quantified the Ni loading at 6.4 wt\%. Fig. 6 shows the EPR spectrum of $\mathrm{NiO} / \mathrm{NPC}$, evidencing the presence of $\mathrm{Ni}^{2+}$ species with a $3 \mathrm{~d}^{8}$ outer shell configuration.

Surface functionalities of the NiO/NPC were examined by FT-IR and shown in Fig. 7. Bands at 2918 and $2846 \mathrm{~cm}^{-1}$ are assigned to C-H stretches from the NPC support, while the broad band at $3423.65 \mathrm{~cm}^{-1}$ is attributed to $\mathrm{OH} / \mathrm{NH}_{2}$ groups. Additional strong bands at 1616 and $1100 \mathrm{~cm}^{-1}$ are assigned to symmetric and asymmetric stretches of carboxylate functions observed by XPS, consistent with previous reports [28], and slightly red-shifted to 1633 and $1106 \mathrm{~cm}^{-1}$ in 
$\mathrm{NiO} / \mathrm{NPC}$, possibly indicating their interaction with $\mathrm{NiO}$ particles at the NPC interface. Fingerprint bands around $600 \mathrm{~cm}^{-1}$ are indicative of Ni-O lattice modes [34].

\subsection{Microcystine-LR degradation}

The catalytic removal of MC-LR by NiO/NPC catalyst via a heterogeneous Fenton oxidative degradation process was subsequently explored as a function of $\mathrm{pH}$ as shown in Fig. 8 . The \%removal efficiency was only moderately $\mathrm{pH}$ sensitive [35], showing a maximum of $89 \%$ degradation after 120 min under acidic conditions, but with good activity (86\% degradation) even at neutral $\mathrm{pH}$. In comparison, Bandala et al [36] only observed $61 \%$ degradation of MC-LR by homogeneous Fenton oxidation after 180 min reaction and employing a low peroxide concentration. While Adriane et al have reported $89 \%$ by solar/photo-Fenton, $77 \%$ by UVA/photo-Fenton, and $84 \%$ by UV-C/ $\mathrm{H}_{2} \mathrm{O}_{2}$ AOT's in aqueous solution. [37]

The impact of hydrogen peroxide concentration was subsequently investigated in Fig. 9. MC-LR removal efficiency was directly proportional to $\left[\mathrm{H}_{2} \mathrm{O}_{2}\right]$ for concentrations below $50 \mathrm{mM}$, presumably due to corresponding hydroxyl radical generation [38], above which a plateau was reached. Fig. 10 shows the impact of NiO/NPC catalyst loading on the heterogeneous Fenton degradation, which shows that the reaction is severely mass-transport limited for loadings above $1 \mathrm{~g} / 0.5 \mathrm{~L}$ (control experiments conducted without hydrogen peroxide evidenced minimal MC-LR adsorption and active site-blocking, accounting for only $0.2 \%$ of the observed catalytic removal). Re-use experiments demonstrated excellent NiO/NPC recyclability, with only a small decrease in the 120 min removal efficiency to around $78 \%$ after two recycles. ICP-OES of the filtrate and spent catalyst recovered after MC-LR oxidative-removal revealed negligible nickel leaching $<0.7 \mathrm{ppm}$ from the parent $\mathrm{NiO} / \mathrm{NPC}$. 


\subsection{Mechanism of MC-LR mineralization}

It is likely that the $\mathrm{NiO}$ component of $\mathrm{NiO} / \mathrm{NPC}$ formed during the materials synthesis plays an important role in the heterogeneous Fenton-like catalytic oxidation of MC-LR. Hydrogen peroxide decomposition and concomitant hydroxyl radical formation likely occurs via electron trapping on the NPC [24] (an extrinsic semiconductor) and reduction of $\mathrm{Ni}^{2+}$ as shown in Eq. (1)

$\mathrm{NiO} / \mathrm{NPC}\left(h_{v b}^{+}\right)+\mathrm{H}_{2} \mathrm{O}_{2} \rightarrow \mathrm{NiO} / \mathrm{NPC}^{*}(\cdot \mathrm{OH})_{a d s}+\mathrm{OH}_{a q}^{-}$

The parallel reaction of molecular oxygen with NiO/NPC material may generate superoxide radical anions as shown in Eq. (2).

$\mathrm{NiO} / \mathrm{NPC}\left(e_{c b}^{-}\right)+\mathrm{O}_{2} \rightarrow \mathrm{NiO} / \mathrm{NPC}\left(\mathrm{O}_{2}^{\bullet^{-}}\right)_{a d s}$

Hydroperoxy radicals are formed by proton abstraction from the MC-LR via reaction with superoxide radical anions as shown in Eqs. (3 and 4).

$\mathrm{NiO} / \mathrm{NPC}\left(\mathrm{O}_{2}^{\bullet^{-}}\right)_{a d s}+\mathrm{H}_{(a d s)}^{+} \rightarrow \mathrm{NiO} / \mathrm{NPC}\left(\mathrm{HO}_{2}^{\bullet}\right)_{a d s}$

$\mathrm{NiO} / \mathrm{NPC}\left(\mathrm{HO}_{2}^{\bullet}\right)_{a d s}+\mathrm{H}_{a q}^{+} \rightarrow \mathrm{NiO} / \mathrm{NPC}\left(2 \mathrm{OH}^{\bullet}\right)_{a d s}$

\section{Conclusions}

In this study, a nanoporous carbon supported nickel catalyst was prepared via chemical activation and hydrothermal treatment. The resulting NiO/NPC catalyst showed good activity toward MC-LR removal in an aqueous medium in the presence of hydrogen peroxide, achieving $89 \%$ degradation of the toxin within 120 min at $\mathrm{pH}$ 3. MC-LR degradation over NiO/NPC was only moderately dependent on $\mathrm{pH}$, but $86 \%$ degradation was still achieved at $\mathrm{pH} 7$, but strongly 
dependent on peroxide concentration, with a maximum activity for $50 \mathrm{mM}\left[\mathrm{H}_{2} \mathrm{O}_{2}\right]$. Nickel leaching from the NiO/NPC catalyst was negligible during the oxidative degradation process, with good activity retained over three recycles evidencing its potential for wastewater depollution.

\section{Acknowledgement}

This work was supported by the National Research Foundation of Korea grant funded by the Kor ea government (MSIP) (No. 2016R1A2B4009122). A.F.L. thanks the EPSRC for financial support (EP/K021796/1, EP/K029525/2). S.K. acknowledges the Royal Society and Science and Engineering Research Board for the award of a Royal Society-SERB "Newton International Fellowship".

\section{References}

[1] L. Zhou, Y. Shao, J. Liu, Z. Ye, H. Zhang, J. Ma, Y. Jia, W. Gao, Y. Li, Preparation and Characterization of Magnetic Porous Carbon Microspheres for Removal of Methylene Blue by a Heterogeneous Fenton Reaction, ACS Applied Materials \& Interfaces, 6 (2014) 7275-7285.

[2] X. Huang, X. Hou, J. Zhao, L. Zhang, Hematite facet confined ferrous ions as high efficient Fenton catalysts to degrade organic contaminants by lowering $\mathrm{H} 2 \mathrm{O} 2$ decomposition energetic span, Applied Catalysis B: Environmental, 181 (2016) 127-137.

[3] F. Persico, M. Sansotera, C.L. Bianchi, C. Cavallotti, W. Navarrini, Photocatalytic activity of TiO2embedded fluorinated transparent coating for oxidation of hydrosoluble pollutants in turbid suspensions, Applied Catalysis B: Environmental, 170-171 (2015) 83-89.

[4] F.F. Dias, A.A.S. Oliveira, A.P. Arcanjo, F.C.C. Moura, J.G.A. Pacheco, Residue-based iron catalyst for the degradation of textile dye via heterogeneous photo-Fenton, Applied Catalysis B: Environmental, 186 (2016) 136-142.

[5] J.B. Carbajo, A.L. Petre, R. Rosal, S. Herrera, P. Letón, E. García-Calvo, A.R. Fernández-Alba, J.A. Perdigón-Melón, Continuous ozonation treatment of ofloxacin: Transformation products, water matrix effect and aquatic toxicity, Journal of Hazardous Materials, 292 (2015) 34-43.

[6] G. Ovejero, A. Rodríguez, A. Vallet, J. García, Catalytic wet air oxidation of a non-azo dye with $\mathrm{Ni} / \mathrm{MgAlO}$ catalyst, Chemical Engineering Journal, 215-216 (2013) 168-173.

[7] Y. Liu, S. Chen, X. Quan, H. Yu, H. Zhao, Y. Zhang, Efficient Mineralization of Perfluorooctanoate by Electro-Fenton with H2O2 Electro-generated on Hierarchically Porous Carbon, Environmental Science \& Technology, 49 (2015) 13528-13533.

[8] P. Nidheesh, R. Gandhimathi, Trends in electro-Fenton process for water and wastewater treatment: an overview, Desalination, 299 (2012) 1-15.

[9] P. Nidheesh, R. Gandhimathi, S. Velmathi, N. Sanjini, Magnetite as a heterogeneous electro Fenton catalyst for the removal of Rhodamine B from aqueous solution, Rsc Advances, 4 (2014) 5698-5708. 
[10] P.V. Nidheesh, R. Gandhimathi, Comparative Removal of Rhodamine B from Aqueous Solution by Electro-Fenton and Electro-Fenton-Like Processes, CLEAN-Soil, Air, Water, 42 (2014) 779-784.

[11] S.J. George, R. Gandhimathi, P.V. Nidheesh, S.T. Ramesh, Electro-Fenton method oxidation of salicylic acid in aqueous solution with graphite electrodes, Environmental Engineering Science, 30 (2013) 750-756.

[12] D. Venu, R. Gandhimathi, P. Nidheesh, S. Ramesh, Treatment of stabilized landfill leachate using peroxicoagulation process, Separation and Purification Technology, 129 (2014) 64-70.

[13] A. Ajmal, I. Majeed, R.N. Malik, H. Idriss, M.A. Nadeem, Principles and mechanisms of photocatalytic dye degradation on TiO2 based photocatalysts: a comparative overview, RSC Advances, 4 (2014) 3700337026.

[14] E. Neyens, J. Baeyens, A review of classic Fenton's peroxidation as an advanced oxidation technique, Journal of Hazardous Materials, 98 (2003) 33-50.

[15] S. Karthikeyan, A. Titus, A. Gnanamani, A.B. Mandal, G. Sekaran, Treatment of textile wastewater by homogeneous and heterogeneous Fenton oxidation processes, Desalination, 281 (2011) 438-445.

[16] Q. Wang, S. Tian, P. Ning, Degradation Mechanism of Methylene Blue in a Heterogeneous Fentonlike Reaction Catalyzed by Ferrocene, Industrial \& Engineering Chemistry Research, 53 (2014) 643-649.

[17] E. Raymundo-Piñero, P. Azaïs, T. Cacciaguerra, D. Cazorla-Amorós, A. Linares-Solano, F. Béguin, KOH and $\mathrm{NaOH}$ activation mechanisms of multiwalled carbon nanotubes with different structural organisation, Carbon, 43 (2005) 786-795.

[18] M.S. Dresselhaus, A. Jorio, M. Hofmann, G. Dresselhaus, R. Saito, Perspectives on Carbon Nanotubes and Graphene Raman Spectroscopy, Nano Letters, 10 (2010) 751-758.

[19] Y. Shao, J. Sui, G. Yin, Y. Gao, Nitrogen-doped carbon nanostructures and their composites as catalytic materials for proton exchange membrane fuel cell, Applied Catalysis B: Environmental, 79 (2008) 89-99.

[20] T. Wang, Z. Dong, T. Fu, Y. Zhao, T. Wang, Y. Wang, Y. Chen, B. Han, W. Ding, Nickel embedded in Ndoped porous carbon for the hydrogenation of nitrobenzene to $\mathrm{p}$-aminophenol in sulphuric acid, Chemical Communications, 51 (2015) 17712-17715.

[21] B.-J. Kim, K.-M. Bae, H.-M. Lee, S.-J. Kang, S.-J. Park, A Study on Toxic Acidic Vapor Removal Behaviors of Continuously Nanostructured Copper/Nickel-Coated Nanoporous Carbons, Journal of Nanomaterials, 2015 (2015) 7.

[22] H. He, S. Yang, K. Yu, Y. Ju, C. Sun, L. Wang, Microwave induced catalytic degradation of crystal violet in nano-nickel dioxide suspensions, Journal of Hazardous Materials, 173 (2010) 393-400.

[23] S.-Q. Liu, B. Xiao, L.-R. Feng, S.-S. Zhou, Z.-G. Chen, C.-B. Liu, F. Chen, Z.-Y. Wu, N. Xu, W.-C. Oh, Z.-D. Meng, Graphene oxide enhances the Fenton-like photocatalytic activity of nickel ferrite for degradation of dyes under visible light irradiation, Carbon, 64 (2013) 197-206.

[24] S. Karthikeyan, D.D. Dionysiou, A.F. Lee, S. Suvitha, P. Maharaja, K. Wilson, G. Sekaran, Hydroxyl radical generation by cactus-like copper oxide nanoporous carbon catalysts for microcystin-LR environmental remediation, Catalysis Science \& Technology, 6 (2016) 530-544.

[25] S. Karthikeyan, R. Boopathy, G. Sekaran, In situ generation of hydroxyl radical by cobalt oxide supported porous carbon enhance removal of refractory organics in tannery dyeing wastewater, Journal of Colloid and Interface Science, 448 (2015) 163-174.

[26] S. Karthikeyan, C.J. Magthalin, A.B. Mandal, G. Sekaran, Controlled synthesis and characterization of electron rich iron(iii) oxide doped nanoporous activated carbon for the catalytic oxidation of aqueous ortho phenylene diamine, RSC Advances, 4 (2014) 19183-19195.

[27] L. Calvo, M.A. Gilarranz, J.A. Casas, A.F. Mohedano, J.J. Rodríguez, Hydrodechlorination of alachlor in water using $\mathrm{Pd}, \mathrm{Ni}$ and $\mathrm{Cu}$ catalysts supported on activated carbon, Applied Catalysis B:

Environmental, 78 (2008) 259-266. 
[28] S. Karthikeyan, R.B. Ahamed, M. Velan, G. Sekaran, Synthesis and characterization of Co-NPAC and in situ hydroxyl radical generation for the oxidation of dye laden wastewater from the leather industry, RSC Advances, 4 (2014) 63354-63366.

[29] S. Karthikeyan, G. Sekaran, In situ generation of a hydroxyl radical by nanoporous activated carbon derived from rice husk for environmental applications: kinetic and thermodynamic constants, Physical Chemistry Chemical Physics, 16 (2014) 3924-3933.

[30] A.P. Grosvenor, M.C. Biesinger, R.S.C. Smart, N.S. Mclntyre, New interpretations of XPS spectra of nickel metal and oxides, Surface Science, 600 (2006) 1771-1779.

[31] P. Veerakumar, R. Madhu, S.-M. Chen, C.-T. Hung, P.-H. Tang, C.-B. Wang, S.-B. Liu, Porous carbonmodified electrodes as highly selective and sensitive sensors for detection of dopamine, Analyst, 139 (2014) 4994-5000.

[32] V. Veeramani, R. Madhu, S.-M. Chen, P. Veerakumar, C.-T. Hung, S.-B. Liu, Heteroatom-enriched porous carbon/nickel oxide nanocomposites as enzyme-free highly sensitive sensors for detection of glucose, Sensors and Actuators B: Chemical, 221 (2015) 1384-1390.

[33] S. Karthikeyan, G. Sekaran, V.K. Gupta, Nanoporous activated carbon fluidized bed catalytic oxidations of aqueous $\mathrm{o}, \mathrm{p}$ and $\mathrm{m}$-cresols: kinetic and thermodynamic studies, Environmental Science and Pollution Research, 20 (2013) 4790-4806.

[34] C.A. Melendres, W. Paden, B. Tani, W. Walczak, On the Structure of the Higher Oxide Forms of Nickel, Journal of The Electrochemical Society, 134 (1987) 762-763.

[35] H. Selçuk, G. Eremektar, S. Meriç, The effect of pre-ozone oxidation on acute toxicity and inert soluble COD fractions of a textile finishing industry wastewater, Journal of Hazardous Materials, 137 (2006) 254-260.

[36] E.R. Bandala, D. Martínez, E. Martınez, D.D. Dionysiou, Degradation of microcystin-LR toxin by Fenton and Photo-Fenton processes, Toxicon, 43 (2004) 829-832.

[37] A.M. de Freitas, C. Sirtori, C.A. Lenz, P.G. Peralta Zamora, Microcystin-LR degradation by solar photo-Fenton, UV-A/photo-Fenton and UV-C/H2O2: a comparative study, Photochemical \& Photobiological Sciences, 12 (2013) 696-702.

[38] S. Wang, A Comparative study of Fenton and Fenton-like reaction kinetics in decolourisation of wastewater, Dyes and Pigments, 76 (2008) 714-720. 


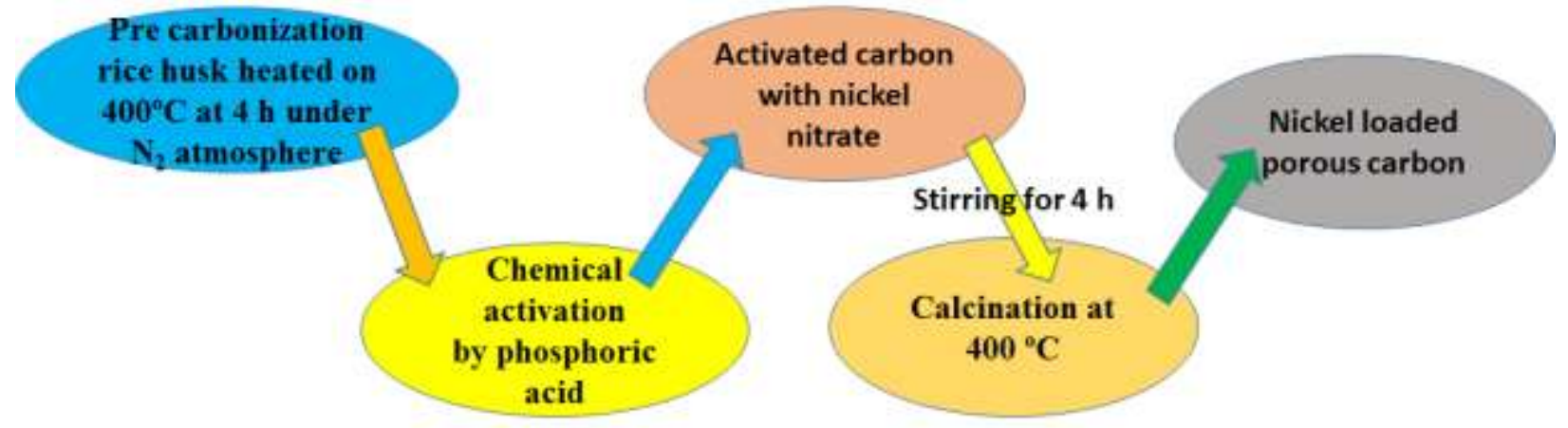

Fig. 1 Schematic illustration for synthesis protocol for the NiO/NPC catalyst 

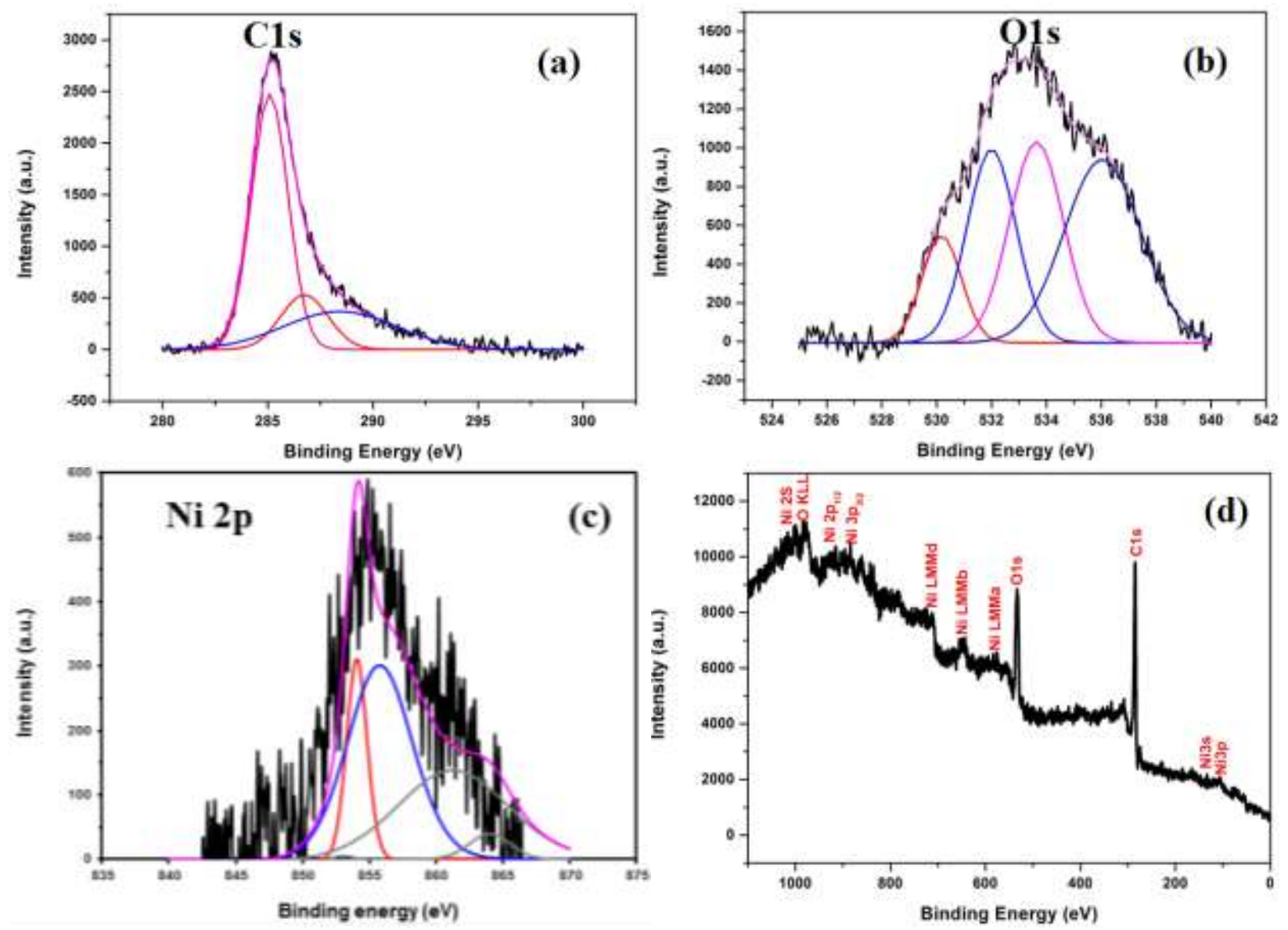

Fig. 2 XP spectra of $\mathrm{NiO} / \mathrm{NPC}$ a) $\mathrm{C} 1 \mathrm{~s}$, b) O1s, c) $\mathrm{Ni} 2 \mathrm{p}$, and d) survey scan spectrum of $\mathrm{NiO} / \mathrm{NPC}$ 


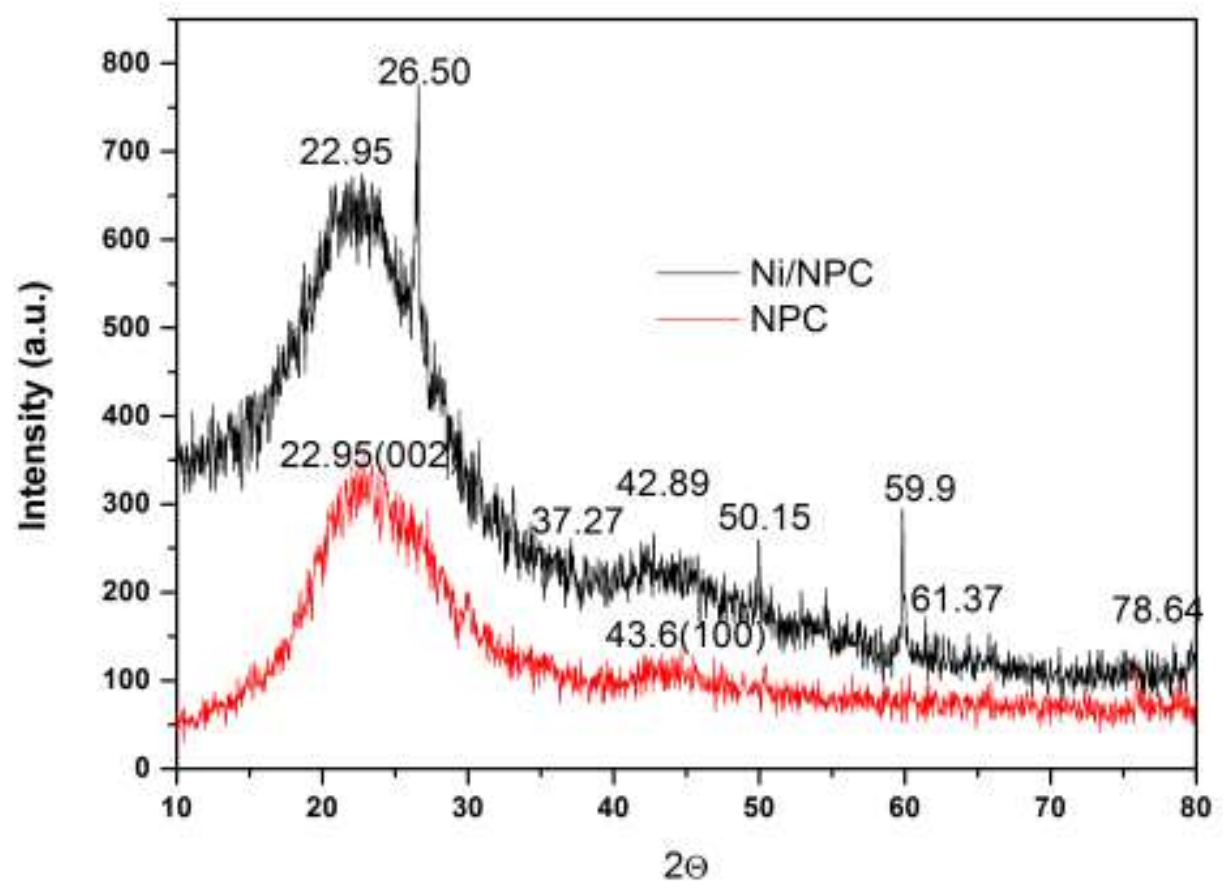

Fig. 3 XRD patterns of NPC and NiO/NPC 

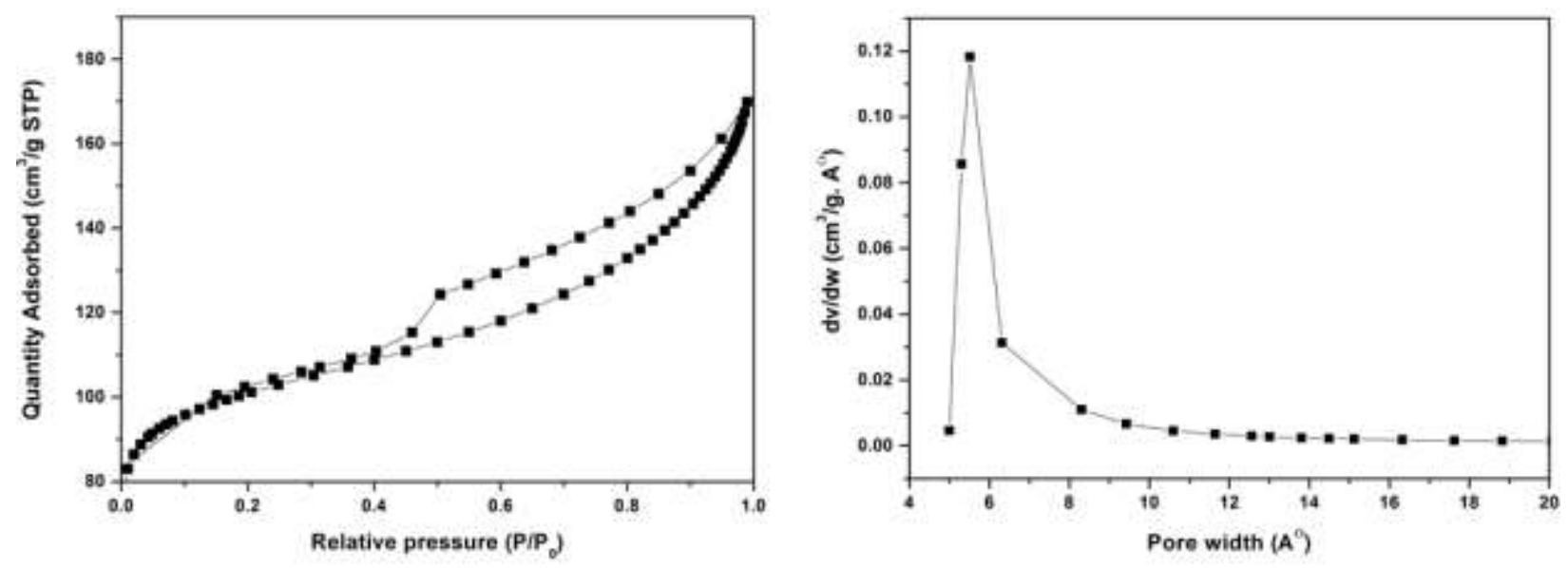

Fig. 4a Adsorption-desorption isotherm of NiO/NPC, b) pore size distribution of NiO/NPC 




Fig. 5 SEM images of a) NPC, b,c) NiO/NPC and d) corresponding EDX spectrum of NiO/NPC 


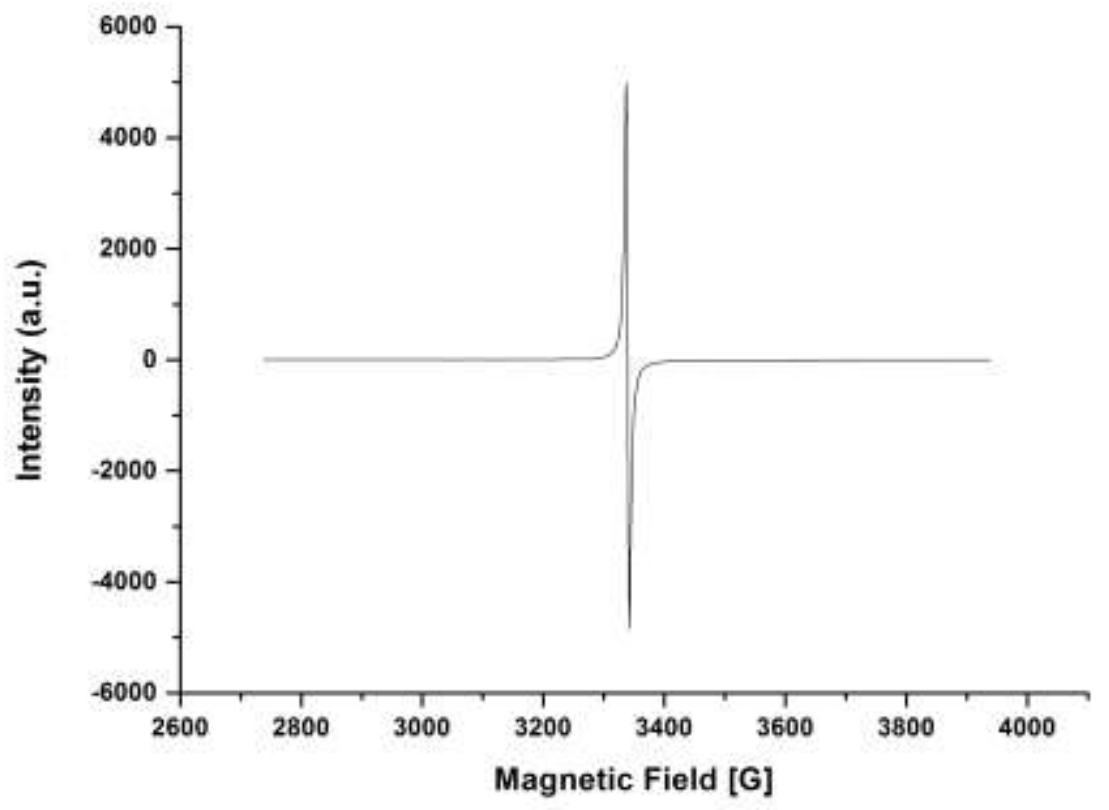

Fig. 6 EPR spectrum of NiO/NPC 


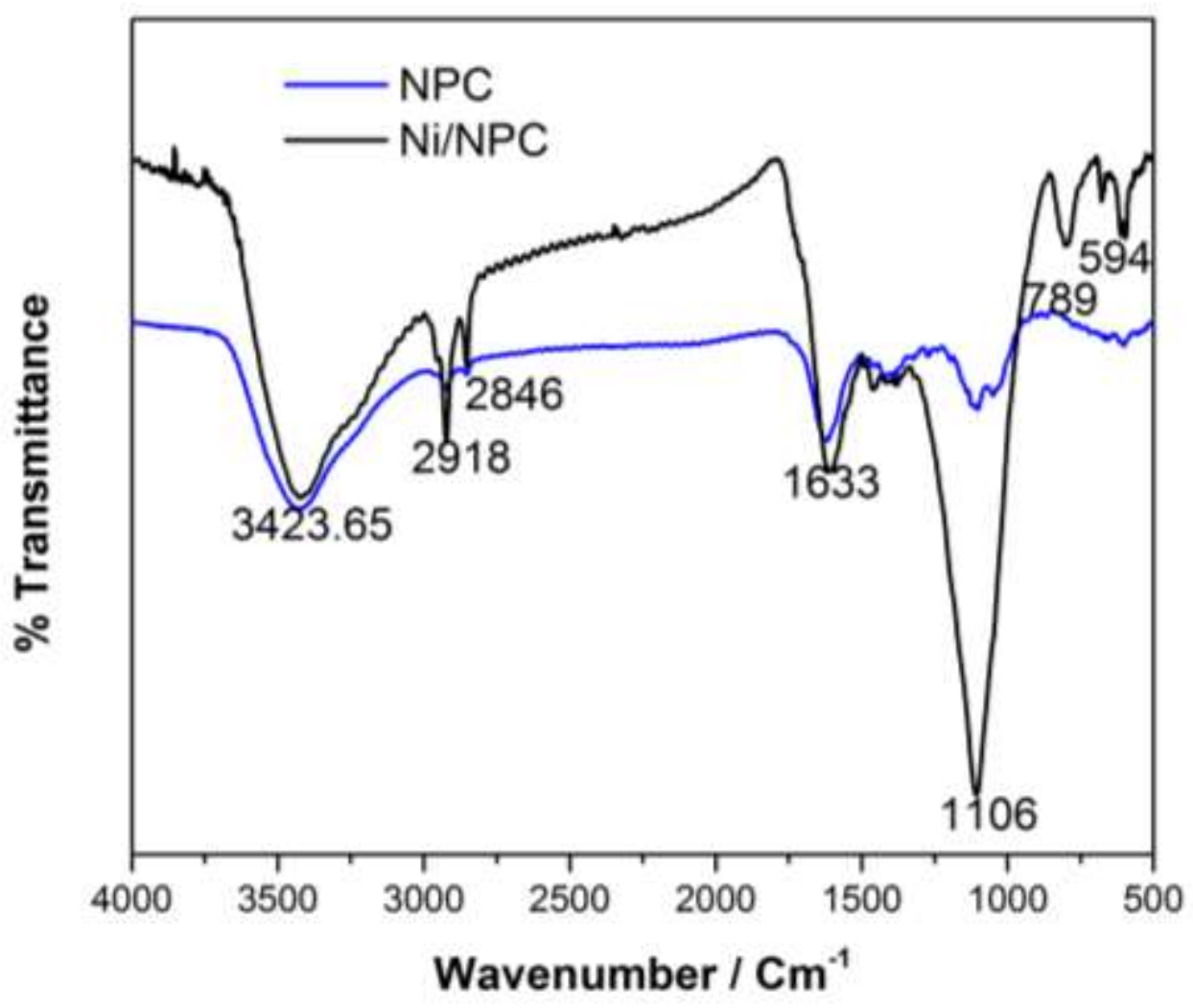

Fig. 7 FT-IR spectra of NPC and NiO/NPC 


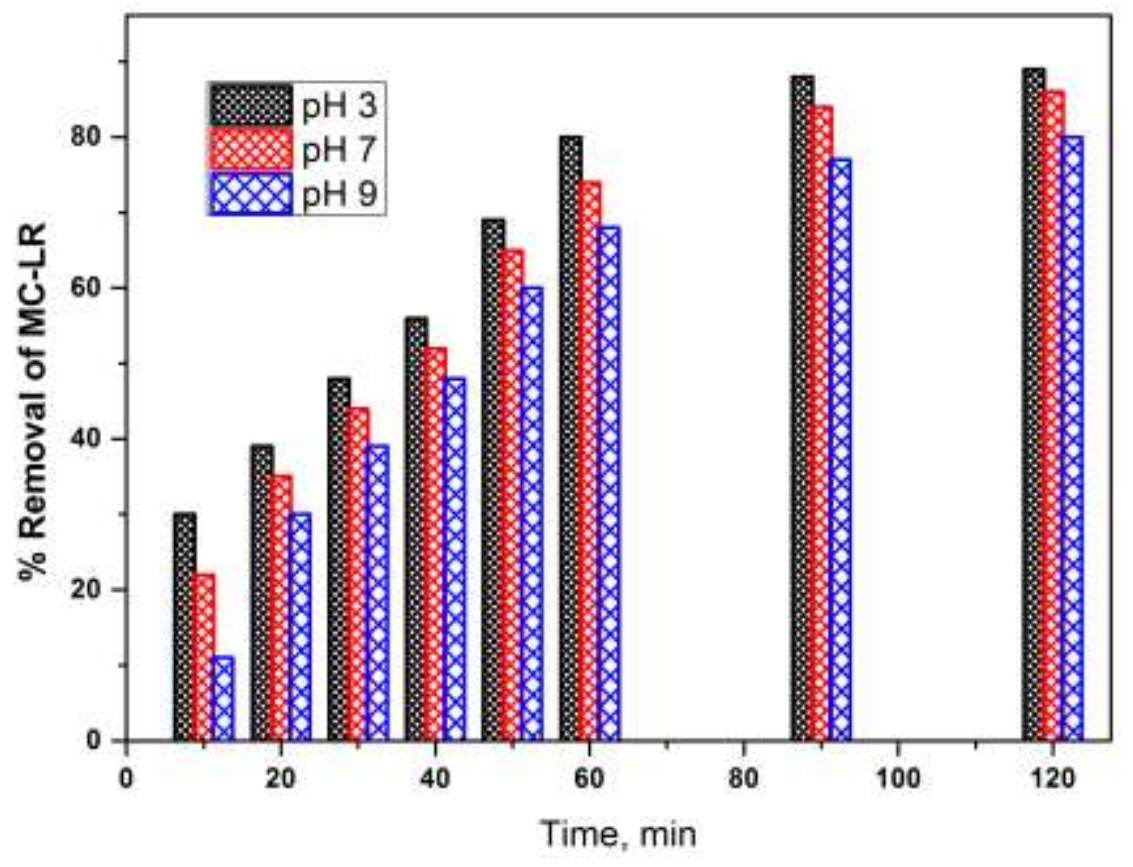

Fig. 8 Effect of $\mathrm{pH}$ on removal of MC-LR. Reaction conditions: $1 \mathrm{~g} / 0.5 \mathrm{~L}$ of NiO/NPC, $50 \mathrm{mM}$ of $\mathrm{H}_{2} \mathrm{O}_{2}$, and $100 \mu \mathrm{g} / \mathrm{L} \mathrm{MC}-\mathrm{LR}$ 


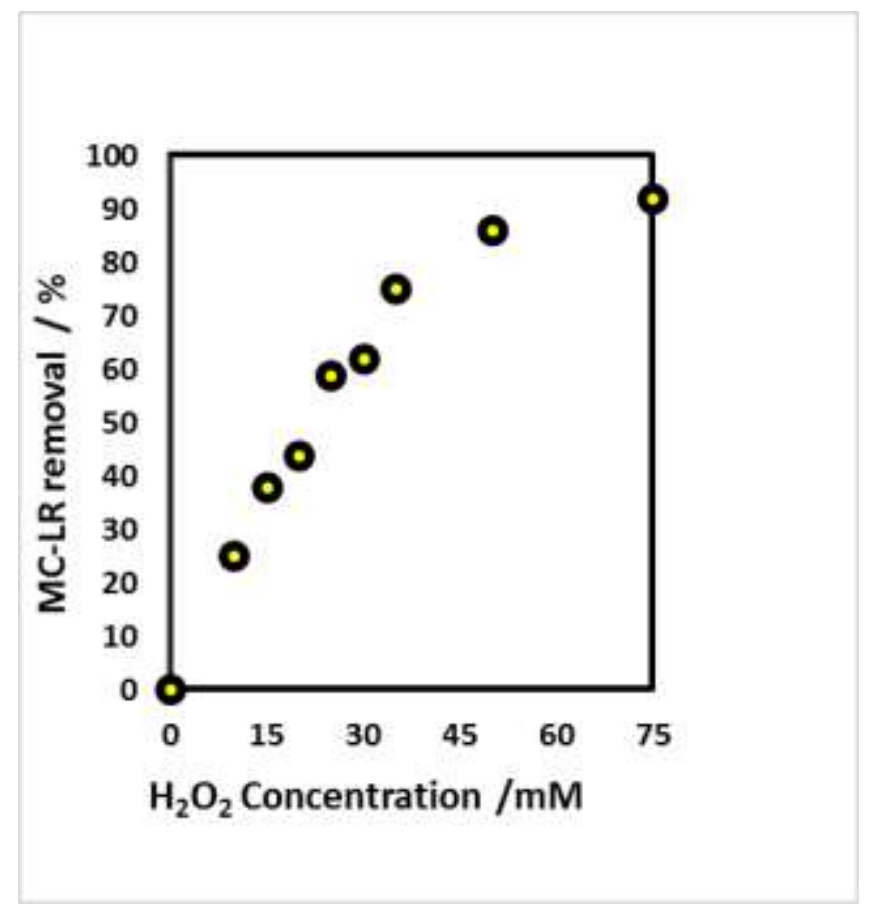

Fig.9 Effect of hydrogen peroxide for removal of MC-LR. Reaction conditions: $1 \mathrm{~g} / 0.5 \mathrm{~L}$ of $\mathrm{NiO} / \mathrm{NPC}, 120$ min reaction, and $100 \mu \mathrm{g} / \mathrm{L}$ MC-LR 

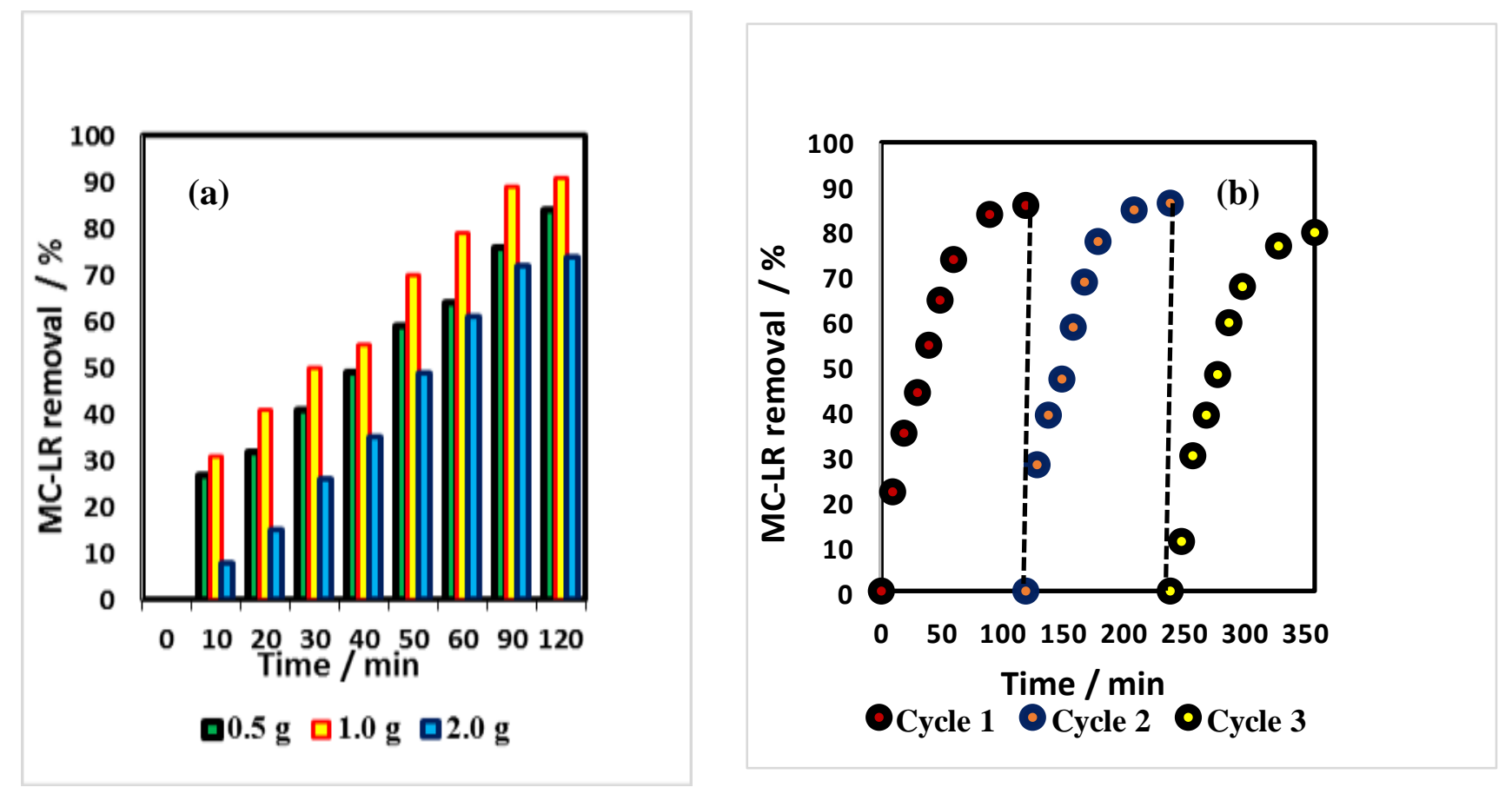

Fig. 10 (a) Effect of catalyst loading (g/0.5 L) on MC-LR removal, and (b) reusability of NiO/NPC. Reaction conditions: $1 \mathrm{~g} / 0.5 \mathrm{~L}$ of NiO/NPC, $50 \mathrm{mM}$ of $\mathrm{H}_{2} \mathrm{O}_{2}$, and $100 \mu \mathrm{g} / \mathrm{L}$ MC-LR 